\title{
7 Tele-evangelism, tele-health and cyberbullying in the wake of the outbreak of COVID-19 in Zimbabwe
}

\author{
Lucia Ponde-Mutsvedu and Sophia Chirongoma
}

\section{Introduction}

The outbreak of COVID-19 has indeed changed human interactions in the 21st century. Although how this epidemic actually originated remains unclear, it is apparent that the epidemic has impacted heavily on human communities and the global economic systems have been torn asunder. What is even more worrisome is that COVID-19 is still in its prime stages with a very high probability of ongoing for an unforeseeable period of time. As noted by Okon (2011), like any other global epidemics, COVID-19 necessitates that humanity be equipped with the dos and don'ts in order to stem the tide of the epidemic. In an endeavour to contain the epidemic, global health institutions such as the World Health Organization (WHO) have disseminated information and guidelines on how to practice physical and social distancing as measures to minimize chances of spreading the coronavirus. Focusing particularly on the African context with particular reference to the Karanga-Shona people in Zimbabwe, this chapter reflects on some of the efforts that have been put into place in order to observe these stipulated measures. The use of Information and Communication Technology (ICT) to bridge the social gap created by these measures will also be deliberated upon. The challenges posed by observing the stipulated guidelines in light of the African understanding of being in community is the focus of discussion in this chapter. Hence, the discussion centres on how the use of Tele-evangelism, Tele-health and other virtual means of making contact impact heavily on the African ethos of living in a community. In this undertaking, the chapter also seeks to weave another strand on the tapestry of "Online religion" in Africa as already deliberated upon by other scholars, particularly Goliama (2010), Asamoah-Gyadu (2015) as well as Sibanda and Hove (2018). This pre-existing literature interrogates the pros and cons of online religion in our contemporary times. In unison with these scholars, this chapter focuses particularly on the Karanga-Shona and how their worldview has been radically reshaped by the stipulated guidelines necessitated by the COVID-19 epidemic. 


\section{Methodology and theoretical framework}

This chapter draws insights from Bronfenbrenner's ecological model and the African ethic of Ubuntu/Unhu as guiding theories. Adopting the ecological model in this chapter helps to illustrate the impact of self-quarantine, social and physical distancing as opposed to the tradition of communal interactions which has been embedded in the African communities since time immemorial (Swearer \& Susan, 2011). Life as presented in the African culture is indeed communal (Mabvurira, 2018). Clearly, the stipulated measures guiding human contact in the wake of COVID-19 are contrary to the African social interactions especially in the family, communal and religious circles. These measures also present major barriers for political gatherings which thrive in numbers.

Bronfenbrenner's ecological theory is anchored on examining how human interactions are linked to one's environment. Initially, his theory was mainly applied when studying the development of children. However, the theory has also been used to analyse the interconnectedness of human relationships in general. Hence, Bronfenbrenner's theory emphasizes on the importance of analysing the interconnections in human communities. This makes this theory relevant in this discussion because it helps to unpack how the "new normal" in the wake of the COVID-19 epidemic disrupts the web of connections within the African communities. The family, school, peers and the social environment play pivotal roles in maintaining the positive vibe to someone who is suffering either emotionally or physically. This is how the ecological model becomes relevant because the experiences of those suffering from ailments related to the coronavirus are inextricably linked to the conditions that the environment is throwing at them. Gaining such information can only help the affected and infected in trying to come to terms with the present situation in a contextualised framework; the social environment.

The ecological theory endorses the interconnectedness amongst families and the environment while the spirit of Ubuntu/Unhu echoes the notion of communitarianism. In this regard, the Ubuntu/Unhu philosophy upholds the importance of the community over the notion of an individual. According to Kimmerle (2006), Ubuntu emphasizes on 'we' in contrast with 'I'. Similarly, Mugumbate and Nyangura (2013:83) define the principle of Ubuntu as "being human through other people." The conclusion reached in this chapter is that the spirit of "Ubuntu" rides on the collective notion. The relationship between the individual and the social environment plays a pivotal role in human relationships. Human beings thrive on each other's encouragement, physical and social contact. Contrary to this, the COVID-19 epidemic has brought about the need to self-quarantine, especially in the event that one has tested positive for the coronavirus. This entails being isolated in an enclosed space, with absolutely no contact even with all those whom one holds so dear. In this chapter, we argue that as African indigenous people who thrive on communal interactions, being required to self-isolate in times 
of illness due to COVID-19 related ailments might leave a permanent void not only on the patient but more so, on those closely related to the patient. This is because they will be agonizing with the harsh reality of the fact that they have been deprived of their duty to care for their loved one in their most crucial time of need. In concurrence with Goliama (2010), we also contend that the stipulated guidelines on maintaining social distance, which underscores that people should neither exchange handshakes nor hugs is totally contrary to the indigenous African concept of Ubuntu//Unhu and being in community. Hence, our chapter resonates with Asamoah-Gyadu (2015) in underlining the fact that the use of tele-evangelism, tele-health services and other non-direct physical space sharing as necessitated by online platforms are inconsistent with the spirit of Ubuntu/Unhu.

\section{Proliferation of information and communication technology (ICT)}

The proliferation of Information and Communication Technology (ICT) has brought about vast advantages in the face of the COVID-19 epidemic. For example, ICT enables individuals to listen to the word of God in the comfort of their own homes by turning on the television, radio or other social media platforms such as WhatsApp, Facebook or Instagram. People are attending church services via Facebook live streaming and they have continued to receive spiritual upliftment. In another vein, families have been maintaining regular communication channels through the use of WhatsApp video calls, Zoom Conferencing and Hangouts. The use of ICT is therefore facilitating constant communication which helps to maintain family and social ties. Consequently, using the virtual platform as a mode of communication is helping to foment the spirit of Ubuntu/Unhu. The idea of interacting with a loved one during a video call or video conference gives both parties comfort and solace. Making connections via the virtual space helps to maintain relationships and to bring loved ones together, especially those who are separated through time and space.

\section{Tele-evangelism}

As noted by Biernatzki (1991), tele-evangelism refers to the process of conveying the Bible message to the people via various forms of media. Similarly, Hoover and Clark (2002) describe tele-evangelism as the mainstreaming of religious activities and messages via the television or a radio. In other words, tele-evangelism focuses on uniting the men and women of God through inspired Bible messages via media. In the contemporary context, the use of television, twitter and Facebook can never be underestimated (Sibanda and Hove, 2018). Globally, tele-evangelism has been in use since time immemorial. Tele-evangelism as highlighted by Okon (2011) is anchored on the importance of the pastor or the sharer of the word, the type of message to be delivered and the audience (those receiving the word). According to Okon 
(2011), televisions are a sure way of conveying Bible based messages to millions of people across the world. In a similar light, Thomas and Lee (2012) aver that the media has been the mainstay of the people's faith in the contemporary world. It has been used as a vehicle to transmit the gospel to the whole world. In this pandemic era, people need to stay abreast with the word of God which keeps encouraging them to hold onto their faith as they go through the trying times. The spirit and the body cannot be separated; thus, it is of great importance for the people of God to maintain a certain grain of faith through the word. Live streaming on Facebook pages, videos and WhatsApp audio also help to disseminate religious messages to the bulk of African communities who either do not have access to or they cannot afford to pay for the DSTV subscription due to financial constraints.

Furthermore, the lockdown regulations in Zimbabwe which limits worshippers to only 50 people in a particular church service leaves the majority without the much needed spiritual caretaking. Consequently, the use of ICT is bridging the gap by bringing the word to different people in various parts of the world via the media. The use of media to share religious messages has sustained the spirituality of most people as they continue to fellowship together as families in their own homes. With just one click, the message is delivered instantly. This has actually helped to build relationships by cementing and increasing family interactions. In one of the audios sent via WhatsApp, a woman recorded a message articulating the goodness of COVID-19; she was rejoicing that due to the lockdown measures, she is now having an opportunity to spend more time with her husband and the children, something that was not possible before then. Others are also welcoming the lockdown restrictions because with limited opportunities for traveling, they are now able to save money as there are no transport costs to and from church. On the other hand, tele-evangelism also saves time, because people will not need to spend time travelling to the church building when the church service is being broadcast online.

In Zimbabwe, various churches and ministries are utilizing tele-evangelism to propagate the gospel especially as the lockdown restrictions have persisted for several months. For instance, the Prophetic Healing Deliverance Ministries (PHD Ministries) through its tele-evangelism arm, Yadhah TV which was originally founded in 2012 is currently making waves not only in Zimbabwe but globally. Likewise, Ezekiel TV, which was founded by Apostle Ezekiel Guti, the founder of ZAOGA (Zimbabwe Assemblies of God) is another powerful ministry. Another really popular tele-evangelism station is Emmanuel TV which was founded in 2006 by Prophet by T.B. Joshua, the Pastor of The Synagogue, Church of All Nations (SCOAN) based in Lagos, Nigeria. It is also the most subscribed Christian ministry channel on YouTube worldwide with well over 1,000,000 subscribers, as of January 2019 (https://www.scoan.org/, Accessed 20 October, 2020). Emmanuel TV has become a household ministry in most Zimbabwean homesteads particularly due to its prophetic, healing and deliverance ministry which 
appeals to the hearts of many amidst the uncertainties compounded by the COVID-19 epidemic. The Seventh Day Adventist Church (SDA) in Zimbabwe which is popularly known for holding annual camp-meetings in August has also been innovative by hosting various virtual camp-meetings spreading between the months of August and September, 2020.

\section{Tele-health}

Wotton (2001) describes tele-health services as health care from a distance. Mars \& Erasmus describe tele-health as the provision of health care over a distance through the use of ICT. The burden of caring for patients who have succumbed to the COVID-19 epidemic in various parts of Africa is real. For most African countries, the COVID-19 epidemic exacerbates the already over-stretched health care facilities (Mars, 2013). More so, as noted by Chirongoma (2016), these strained health care facilities are often staffed by very few medical professionals who were already sighing under the heavy yoke of long working hours, coupled with very poor remuneration, long before the outbreak of the COVID-19 epidemic. Against such a background, access to tele-health services in most parts of Africa becomes scarce due to limited resources and personnel (Mars \& Erasmus, 2012). Wootton (2006) describes Africa as having the "digital divide" obstacle. Several segments of the African communities do not yet have access to efficient and reliable tele-communication networks due to poor infrastructure, which raises challenges in rolling out telehealth services. This is mainly because the health care service providers will be trying to guard against issues of liability, licensure and jurisdiction. However, the use of ICT remains a challenge to most Africans. As such, Wootton (2006) advocates for tele-health, since it breaks the barrier of geography and shortages of health personnel in Africa. In actual fact, the implementation of tele-health comes in handy during the current COVID-19 era, where self-isolation, social and physical distancing and quarantining are the order of the day.

Technology use such as Facebook, Twitter and WhatsApp may fail to reach some of the rural areas in Africa. Whilst mostly the elite are enjoying the broadband access, the bulk of the ordinary African populace regard such a facility as a luxury which they cannot afford. There is therefore need for improving the usage of telephones as this is the easier and faster channel of passing on the information in most African societies. In the 1st world, a wide range of medical consultations can be done either physically or virtually. Hence, most people in the 1st world countries have got the privilege of consulting their medical practitioners either in the comfort of their homes or offices. In this contemporary world, information dissemination is afforded to most people by the use of cell phones and video calling. WhatsApp has been the major transmission device in Africa. However, the downside is that in trying to relay some information, unauthenticated information is also 
transmitted along the way, without verification. Due to the fact that some African societies are rather detached from the outside world, this compromises their capacity to properly sift through and verify the authenticity of some life-giving and life-saving information. For instance, some elderly and rural-based folks are being bombarded with loads of misinformation regarding the genesis or the prevention measures for the COVID-19 epidemic. Others have been misled into believing that alcohol consumption will insulate them from contracting the coronavirus. The continuous help from the young generation to the older one is greatly appreciated as the older generation continue to navigate the ICT pool of information which may be too much to assimilate.

\section{Social media}

Social media is indeed the most important and sustaining mode of communication in the contemporary world. Baruah (2015) postulates it as a means of communication amongst the new generation. As the modern technology has continued on a path of evolution, there is need for everyone to keep abreast with modern technology. Media on the other hand, runs a very high risk of being hijacked and used negatively by peddling lies and uncertified information. It is undisputedly known that the social media has spearheaded false information and some people solely rely on the social media for information sharing. Indeed, this tool can be misused. Technology is like a double-edged sword, on one end it gives connectivity, while on the other, it can be the source of emotional disturbances. Some videos and pictures can actually scare people, help them or cause them to live in fear while the same platforms can be the pillars of strength for some people. Very few people take time to verify information circulating on social media, which can provide pathways for spreading some of the very crude and unreliable information. Technology spearheads the sharing of essential information but at the same time it can facilitate the spreading of false information which can cause unnecessary panic and apathy.

\section{Cyberbullying/pornography}

Zimbabwe, like most African countries, with high literacy, has a generally high rate of cell phone usage as well as access to computers and the internet (POTRAZ, 2014). That high level of access to ICT increases children's vulnerability to cyberbullying. This is particularly so during the current COVID-19 lockdown induced measures which have consequently precipitated the increased usage of computers and cell phones as children continue to do most of their school work online. In Zimbabwe, most private schools have engaged online lessons and that has given the young adults an opportunity to navigate and experiment online, while the parents are at work. Children, including those still in primary school are spending a considerable amount of time watching "Netflix" as a pastime. Spending long hours on Facebook, Twitter and other social media platforms has also become the order of the day as 
children continue to study, research and keep in touch with friends and relatives. The flipside of ICT use is the fact that it has the propensity of becoming addictive. Through excessive ICT use, come some strands of violence and emotional abuse as screen time for both children and families is increased. Studies have shown that the more the screen time, the higher the abuse. The probability of coming across pornography is also high and with this volatile environment, parents are also not in the right space of monitoring what the children are doing at home. Concerns on the bread and butter issues are now on the increase, following closures of companies and businesses.

As the children navigate online, their parents are focusing on bread and butter issues and cyberbullying is indeed stemming in, thereby causing undue emotional strain. The younger generation is more susceptible to cyberbullying as they participate in various online activities without adequate monitoring from the adults. A study by Safaria (2016) found out that advancements of technology exacerbate cyberbullying. Apart from advances in technology, cyberbullying is also precipitated by the generational gap between parents and children, as parents are often behind when it comes to dealing with technology (Ordun, 2015). The ideology behind the use of ICT is that some programmes are not age appropriate, but who will be there to monitor what this young generation are watching? Who monitors these children so as to ensure that we continue to cultivate the right values, beliefs and norms amongst the young generation so as to maintain the African moral fabric? The caregivers' capacity to properly monitor children under their care continues to be compromised as the burdens imposed by the coronavirus weighs in heavily on them.

The generational gap and sometimes the constrained relationships between parents and children where there is no open dialogue often exposes the children to become victims of cyberbullying without their parent's knowledge. As the "Generations" advance for example from X, Y and Z, the later generations are likely to fall prey to cyberbullies because they spend more time on the internet than the antecedent generations. The more time they spend on the internet, the greater the risk to being cyberbullied. Technology indeed has compromised the spirit of Ubuntu among families. Instead of enhancing the inter-generational sharing and mentorship, it is instead causing a rift between parents and children as the children spend countless hours learning information from the media platforms rather than tapping from the older generations. The younger generation has a high affinity to technology and this predisposes them to mental health. Thus, the more they get exposed to technology, the greater the risk to numerous emotional problems and pornography.

\section{The "new normal" runs counter to the spirit of Ubuntu/Unhu}

The COVID-19 pandemic seems to be hovering on earth for a bit longer than originally anticipated. Thus, it's of utmost importance to draw the dos and don'ts so as to enable human life to cope and be able to survive. The normalcy includes, wearing of masks, social distancing, elbow greeting, no embracing 
at funerals, hand washing and many others. All these are an antithesis of the Ubuntu/Unhu cultural values and norms. Suddenly adjusting to these new norms is especially daunting to the older generation who are steeped in their traditional values. Since time immemorial, the indigenous African greeting, particularly among the Shona people in Zimbabwe involves hand shaking. It is a way of showing respect and one cannot claim to have greeted an elderly person without exchanging a proper handshake. Similarly, at funerals, relatives, friends and neighbours are expected to gather at the homestead of the bereaved and to spend several nights there as a sign of solidarity and to comfort the bereaved. What then is prescribed to be the new normal is that we continue to unite and help each other in such predicaments, bearing in mind that we also have to exercise caution by observing social distancing.

The spirit of Ubuntu/Unhu emphasizes on communal interconnectedness and it frowns upon individualism. Hence, the prescribed measures to selfisolate in the event that one suspects that they have been exposed to the coronavirus or after having tested positive to the coronavirus runs contrary to the true spirit of Ubuntu/Unhu. No opportunity to look after a sick loved one, or being required to wear protective clothing such as gloves and masks when interacting with the loved ones smacks of the African interconnected web of relating. More so, being restricted from sharing utensils and other personal effects with a close family member who is either suspected of being infected or is actually infected with the coronavirus does not sound very pleasant in the African traditional context. The notion of the Ubuntu/Unhu ethos takes into cognisance the role of the environment, which in this case is the family. The microsystem (family, peers, and school) takes into cognisance the importance of the immediate environment which includes the family and peers. These interactions are very personal and in this environment, the family which is supposed to take care of each other is required to distance itself as a way of avoiding transmission. The African context has its own social dynamics which require a certain attitude and experience in order to evaluate other people's feelings and experiences. For instance, due to the intertwined nature of African social networks, it can cause a lot of emotional turmoil to realize that a blood sister or brother can be denied entrance into their sibling's homestead because the family is trying to guard against contracting or spreading the coronavirus. This new normalcy can actually strain social relationships as some family members might not see this from the same perspective. Both the behaviour of the infected and the affected and the impact of their dilemmas can be understood in their environmental context.

As noted by Bronfenbrenner, the environment plays an important role in bringing out the best in a human being. As such, the prescribed burial for corpses that would have died due to COVID-19 causes immense turmoil in those who were close to the deceased. The fact that in the early days of the COVID-19 related death, relatives of the deceased were not even allowed to physically attend the burial exacerbated their grief. This is made apparent by the comments made by one of the Zimbabwean women whose relative was 
among the first Zimbabweans to die of COVID-19 complications in April 2020. She expressed the grief and perplexity in the following words, "Mukoma wangu kuvigwa muplastic sembwa here veduwe!" [It is heart-wrenching that my brother was buried in a plastic bag, he was treated like a dog!] (Interview with an Anonymous Source). Another incident that drew massive social media attention occurred in Harare in June 2020 whereby a young Shona man hysterically protested at the graveyard after having been informed that his deceased grandmother's corpse was forbidden by the health restrictions to lie in state at their homestead because she had tested positive to the coronavirus. The widely circulated video clip which was recorded at the graveyard when the young man was making a scene whilst pleading for permission from the law enforcement agents to be allowed to accord his grandmother a "decent" burial made a social media sensation. Whilst on one hand some viewers heavily critiqued this young man for being insensible, others also sympathized with him by arguing that from a Shona cultural point of view, his protests were justified. These are some of the scenarios which are emitting the "Ubuntu spirit" and culturally, it's not easy for the Shona people who have their own values and beliefs to go through this kind of lamentation. The African notion of having loads of people at a funeral is regarded as "kuchemwa kwakanaka" [a powerful and moving send-off]. Normally, the Shona people perceive a huge crowd of mourners as a sign of the "power of love."

Clearly, the regulation that COVID-19 corpses are supposed to be buried within 24 hours has caused heartache beyond measure for most indigenous African people. This is mainly because most indigenous Africans are used to gathering at funerals, sometimes for more than three days which gives them an opportunity to perform their traditional ceremonies. Regrettably, due to COVID-19, they are being deprived of such opportunities, this leaves most bereaved people devastated and feeling lost. Not being able to actively participate in the burial rituals and being deprived of the opportunity to see a loved one being laid to rest leaves the bereaved with deep emotional wounds. This also presents a major barrier towards getting closure, particularly to those who were close to the deceased. The African communitarian spirit emphasizes the importance of family members and friends visiting each other in their homes and also in the hospital in the event that someone has fallen ill and has been admitted in hospital. This presents a platform for them to offer each other comfort and encouragement. Unfortunately, most of these social interactions have been ground to a halt by the restrictions imposed due to the COVID-19 social distancing measures.

Bronfenbrenner's mesosystem upholds the essence of relationships among the loved ones, which in this case are the parents, teachers and the children. Since the focus is on the relationships and interlinks between those that surround the individual, there is need to maintain a balance between health care and relationships. Failure to have such a balance may result in disequilibrium of the system. Drawing from Bronfenbrenner's ecosystem (indirect environment), a person can take it out on another person because of some unresolved 
issues in his or her life. For instance, if someone has contracted the disease, one may find himself/herself, lashing out on the very person who is genuinely trying to help them out. Just the news that one has tested positive for the coronavirus might take a huge toll on someone. The microsystem, (social and cultural values) and chronosystem (changes over time) play an important role in the shaping of human behaviour. The accumulation of values, beliefs and ideas can never be underestimated for it plays a major role in an adult's life. A change which might befall a family, like in the case of death, can take a huge toll on those who are left behind. A little change in the family structure can revolutionise everything in a family set up. There is therefore need for every family to learn how to resile in such an environment.

Gender relations are another aspect of human relationships that have been heavily impacted by the COVID-19 epidemic. Since the onset of the lockdown measures, the available global and regional statistics reveal a high rise of women and children abuse, and Zimbabwe is no exception. The pandemic did not only alter the people's social lives, but it has precipitated the rates of suicidal tendencies as caregivers lose either their jobs or sources of livelihoods. As the old adage goes, "an idle mind is the devil's workshop," consequently, in some instances, those who have lost their means of sustenance have resorted to crime and violence. Idle time has been increased and that places most people on the verge of committing crime as they struggle to fend for their families.

Furthermore, due to its oral transmission and in the absence of a wellestablished treatment or cure, there is stigma associated with COVID-19. Upon announcement by the health sector personnel that one has contracted the disease, those who are around you tend to distant themselves. Some of these announcements by the health sector exacerbates everything as most WhatsApp groups will disseminate prejudiced information like a veld fire, which exposes the infected individual to the vulnerability of stigma and discrimination.

There is also need for continuous conscientization especially for some conservative religious groups which adamantly defy the stipulated lockdown measures. A case in point is the unfortunate incident that led to the death of three male members of the Sungano Apostolic Church in Mutare, Zimbabwe during the early days of the lockdown phase in April 2020. As reported by several Zimbabwean newspapers, the Manicaland police spokesperson Inspector Tavhiringwa Kokohwa confirmed that the deceased trio were part of a ten member team that had gone to Murahwa Hill in Mutare to observe ten days of prayer and fasting in a cave. They lit a fire which gathered smoke inside the cave resulting in these three men choking to death. Those who lived to tell the tale are the ones who eventually reported the incident to the local police (Masekesa, 2020).

\section{Conclusion}

The outbreak of COVID-19 has impacted heavily on human communities worldwide. Apart from very few advantages which entail increasing family time 
and drawing families together, the disadvantages however outweigh the advantages. In the indigenous African communities, for instance among the Shona, most of the social distancing regulations impinge on their deeply cherished norms and values. For most indigenous communities, particularly in Southern Africa, being required to desist from exchanging handshakes, hugging and being restrained from gathering in numbers at a funeral is tantamount to touching their raw nerves. The introduction of ICT has played a pivotal role in establishing a smooth and easy access to information, at churches, gatherings, and medical institutions as well as facilitating individual daily communication. Though it seems very hard to adapt to the new normal, the harsh reality of the matter is that if human communities wish to survive this catastrophe, difficult as it is, we simply have to learn to adjust to the new way of being in the world. Appreciating the gift of life and exercising responsible stewardship for our lives, our loved ones' lives and the lives of all those we interact with as we await the eventual harnessing of the epidemic should be our main goal. Now, more than ever, there is a pertinent need for information dissemination which is accurate, especially to those in the very remote areas who are still living either under the blanket of ignorance or those who are still in denial regarding the gravity of the challenges and threats presented by the novel coronavirus. Clearly, COVID-19 is a wakeup call to the human race, and the earlier we get it, the better. Being alert to these facts of life will help us to understand the nature of the problem and to take the requisite corrective action.

The African communal understanding is that people live for each other, hence, the African proverb, "it takes a village to raise a child." Simply put, relationship building and interconnectedness as emphasized in Bronfenbrenner's ecological model are the treasured right ingredients for positive human interactions in the African community. Whilst realistically upholding the spirit of Ubuntu, as African indigenous communities, we also need to acknowledge that the earlier we all learn how to adapt to this new normalcy the better, because it's going to be a long journey before most people can embrace reality. The concept of individualism has come in its full force through this very pandemic and so we need to adjust for our own good and for posterity's sake. The above discussion contributes to the current national and international drive to raise awareness in regard to COVID-19 and reduce the mortality rate especially in the spirit of the African community.

\section{References}

Asamoah-Gyadu, J. K. (2015). “"We are on the internet”: Contemporary Pentecostalism in Africa and the new culture of Online Religion" in New Media and Religious Transformations in Africa (eds) Rosalind I. J. Hackett and Benjamin F. Soares, Bloomington, Indiana: Indiana University Press, 157-170.

Baruah, S. (2012). Effectiveness of social media as a tool of communication and its potential for technology enabled connections: A micro-level study. International Journal of Scientific and Research Publications, 2(5), 1-10, May 20121 ISSN 2250-3153. 
Biernatzki, W. E. (1991). Televagelism and the religious uses of television. Communication Research Trends. Communication Research, 11(1).

Chirongoma, S. (2016). "Exploring the impact of economic and socio-political development on people's health and well-being: A case study of the Karanga people in Masvingo, Zimbabwe" in HTS Theological Studies Special Issue on Engaging Development: Contributions to a Critical Theological and Religious Debate (eds) Afe Adogame and Ignatius Swart (Volume 72, Issue 3, pp. 1-9)

Goliama, C. M. (2010). Where Are You Africa?: Church and Society in the Mobile Phone Age. African Books Collective, 71-110.

Hoover, S., \& Clark, L. (2002). Practicing Religion in the Age of the Media: Explorations in Media, Religion, and Culture. New York City: Columbia University Press.

Kimmerle, H. (2006). Ubuntu and Communalism in African philosophy and art. Prophesies and Protest-Ubuntu in Glocal Management, 79-91.

Mabvurira, V. (2018). Making sense of African thought in social work practice in Zimbabwe: Towards professional decolonisation. International Social Work.

Mars, M. (2013). Telemedicine and advances in urban and rural healthcare delivery in Africa. Progress in Cardiovascular Diseases, 326-335.

Mars, M., \& Erasmus, L. (2012). Telemedicine can lower health care costs in Africa. Innovate, 32-33.

Masekesa, C. (2020). "Lockdown: 3 Apostolic church members suffocate to death" https://zimmorningpost.com/lockdown-3-apostolic-church-memberssuffocate-to-death/ April 14, 2020

Mugumbate, J., \& Nyanguru, A. (2013). Exploring African philosophy: The value of Ubuntu in social work. African Journal of Social Work, 3(1), 82-100.

Okon, G. (2011). Religion, media and politics in Africa. Teleevangelism and the socio-political mobilization of pentecostals in Port Harcourt metropolis: A KAP Survey. Politics and Religion, 5(1), 2-475.

Ordun, G. (2015). Millenial (Gen Y) Consumer behavior their shopping preferences and perceptual maps associated with brand loyalty. Canadian Social Science, $40-55$.

Potraz, Z. (2014). Information and Communication Technology (ICT) Household Survey 2014 Access by Households and Use by Individuals. Harare. Zimbabwe: Zimbabwe National Statistics Agency (ZIMSTAT) and Postal and Telecommunications Regulatory Authority of Zimbabwe (POTRAZ).

Safaria, R. (2016). Prevalence and Impact of cyberbullying in a sample of Indonesian junior high school students. The Turkish Online Journal of Educational Technology, 15(1).

Sibanda, F., \& Hove E.F. (2018). Unlocking the media and the politics of televangelism in Zimbabwe: A contemporary discourse in Power in Contemporary Zimbabwe (eds) E. Masitera and F. Sibanda. Routledge, 149-165.

Swearer, N., \& Susan, M. (2011). Risk Factors for and Outcomes of Bullying and Victimization. Educational Psychology Papers and Publications, 132, 1-9.

The Synagogue, Church of All Nations (SCOAN). https://www.scoan.org/ Accessed 20 October, 2020.

Thomas, P., \& Lee, P. (2012). In Global and Local Televangelism: An Introduction. In Global and Local Televangelism (pp. 1-17). London: Palgrave Macmillan. 